\title{
Diablotexto
}

\section{En torno a la identidad inestable del sujeto que viaja y escribe hoy en día: el caso de Miquel Silvestre}

On the unstable identity of the travel writer nowadays: the case of Miquel Silvestre

\author{
KAROLINA ZYGMUNT \\ SWPS UNIWERSYTET HUMANISTYCZNOSPOLECZNY
}

\begin{abstract}
Resumen: El poder transformador del viaje y de su escritura parecen innegables. Ambas experiencias llevan al sujeto que las realiza a experimentarse, cuestionarse e intentar definirse. No obstante, en el caso de quienes viajan y escriben hoy en día, también la pregunta por el propio estatus profesional puede llegar a ser una cuestión identitaria. En este trabajo, para examinar esta compleja relación entre viajar, escribir, trabajar, vivir y autodefinirse, se analizará la figura de Miquel Silvestre, autor que ejemplifica la búsqueda de identidad personal a través de la profesionalización de su labor de escribir sobre los viajes. En el caso de Silvestre, convertirse en un escritor de viajes profesional significa construirse como sujeto, lo que afecta y modifica tanto su escritura como su experiencia del viaje, tal y como se ve reflejado en sus relatos de viajes La emoción del nómada (2013) y Nómada en Samarkanda (2016).
\end{abstract}

Palabras clave: Miquel Silvestre, viaje, identidad, relato de viajes, escritor de viajes profesional.

Abstract: The transformative power of travel and travel writing seems to be undeniable. Both experiences imply that the subject questions himself, experiences, and tries to define himself. However, in the case of those who travel and write today, the professional status can also become a question of identity. In this work, in order to examine this complex relationship between traveling, writing, working, living and defining oneself, the figure of Miquel Silvestre will be analyzed. This author exemplifies the search for personal identity through the professionalization of his activity of writing about travel. In the case of Silvestre, becoming a professional travel writer means constructing himself as a subject, which affects and modifies both his writing and his travel experience, as clearly reflected in his travelogues La emoción del nómada (2013) and Nómada en Samarkanda (2016).

Key words: Miquel Silvestre, travel, identity, travelogue, professional travel writer. 


\title{
El poder transformador de la experiencia del viaje
}

El viaje es tradicionalmente considerado una de las experiencias vitales con más poder transformador y en la que más claramente se puede observar el proceso de (de)construcción del sujeto que lo realiza. La alteridad, indisolublemente unida a la experiencia del viaje, hace que el sujeto tenga que replantearse la relación con su entorno y con uno mismo.

A lo largo de la historia, se ha asociado el desplazamiento geográfico al desplazamiento interior de quien viajaba. Recordemos que ya en el siglo XVIII, para muchos autores, el viaje se revelaba fundamental en la creación del carácter del hombre. Jean-Jacques Rousseau afirmaba que "los viajes impulsan el carácter hacia su inclinación, y acaban por hacer al hombre bueno o malo. Quien vuelve de correr mucho es a su vuelta lo que será durante su vida..." (1998 [1762]: 682). Siglos más tarde, se sigue insistiendo en este poder transformador del viaje como una experiencia íntima, donde quien lo realiza "no puede separarse de su ser" (Onfray, 2016 [2007]: 72). Por esta razón, parece cierto que "no hay forma de salir ileso de la lucha contra las fronteras, de la suerte de ver el mundo, del encuentro con los Otros. El viaje es una huella" (González-Rivera, 2019: 13). Además, no es solo el conocimiento que siempre conlleva esta experiencia, sino también su propia forma y las leyes que la rigen, lo que produce la transformación. Tal y como comenta Jaume Peris Blanes:

\begin{abstract}
No se trataba de que el sujeto adquiriera un saber a lo largo del viaje, sino de que esta adquisición de saber que sea la experiencia viajera cambiaría para siempre la titularidad del sujeto que se hacía cargo de ella. Esto es, que la propia dinámica del viaje, independientemente de los conocimientos que en ella se adquirieran, producía un sujeto nuevo, inexistente anteriormente y articulado en torno a elementos que antes no estaban presentes en él. (2010: 8)
\end{abstract}

\section{El relato de viajes y su "sujeto de doble experiencia"}

En el caso de la puesta por escrito de la experiencia del viaje esta (de)construcción de la identidad del sujeto se realiza en dos dimensiones: afecta tanto al que viaja como al que relata el viaje. Curiosamente, en las obras que se analizarán en este estudio, estos dos sujetos coinciden en la misma persona, ya que, hablando del relato de viajes pensamos, siguiendo a Luis AlburquerqueGarcía, en los textos factuales que constituyen testimonios de una experiencia 
vivida$^{1}$. Se trata de relatos en los que quien realiza el viaje decide ponerlo en palabras presentándolo en forma de un testimonio escrito. En este grupo de textos los papeles de viajero y escritor se mezclan y confunden: estamos ante un escritor que es al mismo tiempo el protagonista de su historia, y ante un viajero que es también el relator de su propia experiencia. Por esta razón, Alburquerque-García habla del autor de un relato de viajes como "un sujeto de doble experiencia":

El "relato de viajes", recordamos, contiene un sujeto de doble experiencia: el viaje y la escritura. Es un sujeto de doble instancia: sujeto viajero, individual e irreemplazable que, además, escribe esa experiencia. Su estatuto ficcional es ciertamente peculiar. Se trata del hombre de carne y hueso, sin mediación de ningún otro tipo de voz imaginaria. (2011: 29)

También Pilar Rubio destaca la gran importancia de este elemento autobiográfico del relato, considerándolo consustancial y definitorio de la narrativa de viaje:

pues no sucede abiertamente en otras áreas literarias que el propio autor se constituya en personaje central de la narración, al ser su protagonista absoluto. La consecuencia inmediata del desdoblamiento del autor es la posibilidad de experimentar en sí mismo el sentimiento de alteridad, una circunstancia especular que puede llegar a modificar seriamente su proyecto narrativo... (2006: 252)

No solo los críticos españoles señalan esta particularidad del género viático². Desde el ámbito anglosajón, Tim Youngs indica que "travel writers have to make decisions on how to deal with several matters intrinsic to their genre" (2013: 158). Según este crítico, la aparición de la figura del narrador es la solución más frecuente para resolver el conflicto autor-protagonista. No obstante,

\footnotetext{
${ }^{1}$ La definición del género y la delimitación de sus límites han generado un gran debate entre los críticos de la literatura de viajes. En este estudio, seguimos la propuesta de Alburquerque-García, según el cual la "literatura de viajes" abarca todo un conjunto de textos de viajes tanto verídicos como ficcionales. Dentro de este grupo, la ficción literaria daría lugar a "las novelas de viaje", mientras que los "relatos de viajes" serían los testimonios de una experiencia vivida. En este contexto el "relato de viajes" se revela como una noción mucho más específica, limitada a relatos factuales, dentro del concepto general de "literatura de viajes". Para más información véase Alburquerque-García (2006, 2011, 2015).

Junto a los estudios de Alburquerque-García, para el panorama general de la discusión sobre el género de la literatura de viajes puede consultarse, entre otros, Richard (1981), Regales Serna (1983), Pérez Priego (1984), Beltrán (1991), Carrizo Rueda (1997), Peñate (2004), Champeau (2004), Colombi (2006), Almarcegui (2008) y Rubio Martín (2011).

${ }^{2}$ Aunque esta acepción no se recoge en el DRAE, en este trabajo utilizaremos el término "viático" en el sentido "referente al viaje, propio del viaje", tal y como lo han hecho otros autores, como por ejemplo, Julio Peñate (2015) que hablaba de "relato viático", "texto viático", "discurso viático", "libro viático" y "escenarios viáticos".
} 
la decisión de cómo contar su historia y si utilizar la primera o la tercera persona para referirse a las propias vivencias no es el único reto de la escritura de viaje. El relator-protagonista tiene que decidir qué cuenta de su experiencia y qué calla, qué visión de sí mismo presenta y qué imágenes de su viaje quiere transmitir al lector $^{3}$. Asimismo, además de esta tensión entre el autor y el protagonista de su propia historia, los escritores de viajes, tal y como señala Carl Thompson, se ven obligados a presentar su experiencia "in an enjoyable, or at least easily digestible way" (2011: 27).

Junto a la necesidad de ajustar su proyecto narrativo a estas circunstancias inexistentes en el mundo de la ficción, el autor de relatos de viajes experimenta una sensación de alteridad y entra en una relación nada habitual con su propio yo: "pues el autor se experimenta a sí mismo y durante el viaje como el otro, el personaje, y a la hora de la escritura como el autor que debe controlar a su personaje" (Rubio, 2006: 252).

De esta forma, tanto la propia experiencia del viaje como su puesta en el discurso contribuyen a la transformación de quien viaja y escribe y forman parte de un complejo proceso de (de)construcción de su identidad. Esta relación tan cercana entre viajar y escribir, esta frontera tan borrosa entre ser el autor y el protagonista de su propia experiencia, más allá de las consecuencias en la forma del relato (la selección de la materia contada, la aparición de la retrospección, el uso de la paratextualidad e intertextualidad, etc.) provoca un conflicto en el propio sujeto que tiene que definirse de alguna manera, sentirse más relacionado con alguna de estas dos facetas tan unidas. ¿Se siente viajero o escritor? ¿El viaje es una excusa para escribir o la escritura es tan solo una consecuencia del viaje?

\footnotetext{
${ }^{3}$ En el panorama de la literatura de viajes actual podemos observar claramente que mientras unos autores asumen todo el protagonismo, elaborando un clarísimo discurso del yo, otros intentan no ocupar el centro del relato y le dan la voz al otro, creando, de esta manera, un texto mucho más polifónico. Para más información puede consultarse Zygmunt (2021).
} 


\section{Entenderse, identificarse y definirse como un escritor profesional de viajes: el caso de Miquel Silvestre}

Ante este poder transformador no solo de la experiencia del viaje, sino también de su puesta en palabras, así como dado el conflicto que estas dos realidades tan cercanas pueden provocar en el sujeto, en este trabajo nos preguntaremos por la identidad, muchas veces en pugna, de los autores de los relatos de viajes. ¿Quién es el que viaja y escribe hoy en día? ¿Cómo se define a sí mismo? ¿Se considera viajero o escritor? ¿Le interesa resaltar más una faceta que otra? ¿Con cuál de los dos papeles se identifica más? ¿Su identidad resulta conflictiva, vive una crisis asociada a ella?

Debido a su gran heterogeneidad, el mundo del relato de viajes se revela como un universo lleno de confusión en cuanto al estatus de los autores de estos textos. Junto a viajeros sin aspiraciones literarias que, siguiendo la idea de Benjamin (1972), al "tener algo que contar", ponen en palabras su experiencia, podemos hablar también de la profesionalización de la escritura de viajes.

En este contexto, hace ya algunos años, Luce Boulnois hablaba de "una nueva generación de caballeros errantes: los viajeros-reporteros-escritores, que gustaban de una vida libre e independiente, razonablemente solitarios, costeando su vida material con la venta de sus libros, fotos, artículos, reportajes y conferencias" (2004 [2001]: 393). También Julio Peñate señala la aparición de la figura del "escritor profesional o semiprofesional del viaje":

como nunca antes, el autor se desplaza para escribir un libro y tiende a mirar las cosas con esa perspectiva. Ya a lo largo de los últimos 150 años ha podido viajar para alimentar su crónica periodística, aunque es en el último siglo, y más bien en su segunda mitad, cuando más tiende a embarcarse con el proyecto de libro: es la emergencia del escritor profesional o semiprofesional del viaje. Firmas como las de Leguineche, Reverte, Pancorbo, Moret, Esteva, Miquel Silvestre, Eduardo Campos, etc., así lo subrayan. (2015: 53) ${ }^{4}$

\footnotetext{
4 Junto a los autores mencionados por Peñate, entre los escritores de viajes consolidados, considerados ya profesionales en su oficio, podemos destacar, entre otros, a Julio Llamazares, Juan Pedro Aparicio, José María Merino, Lorenzo Silva, Jordi Carrión, Patricia Almarcegui y, en el ámbito internacional, a Paul Theroux, Lawrence Osborne, Patrick Leigh Fermor, Cees Nooteboom o Colin Thubron.
} 
Entre la nómina de quienes, según Peñate, se consagran a la profesión de "escritor profesional o semiprofesional del viaje" aparece Miquel Silvestre, el caso al que dedicaremos este trabajo.

La figura de Silvestre resulta muy interesante en el panorama de autores de relatos de viajes actuales, ya que él mismo convierte la pregunta por su relación con el viaje y la escritura en una cuestión identitaria. En su caso, identificarse con la etiqueta del viajero-escritor y asumir plenamente este papel se relaciona con un cambio vital fundamental. Silvestre se revela como un ejemplo de la búsqueda de identidad personal a través de la profesionalización de su labor de escribir sobre los viajes. Su figura e inevitablemente sus textos ilustran muy bien esta compleja relación entre vivir, trabajar, viajar y escribir.

Miquel Silvestre, el sujeto en cuya trayectoria queremos detenernos para reflexionar sobre la identidad inestable y en transformación de quien viaja y escribe hoy en día, es autor de varios relatos de viajes, de los cuales los que nos ocupan serán La emoción del nómada (2013) y Nómada en Samarkanda (2016). Los dos libros recogen el testimonio de su viaje en solitario, realizado en moto por los territorios de Asia Central, y cuya meta, en ambos casos, es la ciudad de Samarcanda 5 .

Cuando conocemos a Miquel Silvestre en La emoción del nómada (2013) es un funcionario (registrador de la propiedad) que aprovecha una excedencia en el trabajo para recorrer en moto los territorios de Asia Central y describir su experiencia. Durante este viaje toma la decisión de convertirse en un escritor profesional de libros de viajes. Las experiencias de este primer viaje hacen que Silvestre quiera dejar su oficio para hacer del desplazamiento y de la escritura su principal modus vivendi. Este propósito se consolida y refuerza en su siguiente obra Nómada en Samarkanda (2016) que puede considerarse el efecto de este cambio de vida. En ella, el autor ya habla de sí mismo como un viajero o aventurero profesional.

\footnotetext{
${ }^{5}$ Silvestre, en el título de su obra, utiliza la forma "Samarkanda", pero a lo largo de su texto habla de "Samarcanda". En este trabajo, siempre emplearemos la segunda grafía para referirnos a este topónimo, pero respetaremos la grafía original del título de Silvestre.
} 
Silvestre, cuando empieza a viajar y escribir, no se conforma con ser tan solo un viajero que deja testimonio escrito de su experiencia, sino que muestra un claro deseo de profesionalizarse y unirse a la nómina de los escritores del género. Esta decisión de dedicarse a la escritura de viaje de forma profesional resulta clave y condiciona tanto su forma de viajar como de escribir. Además, las reflexiones sobre la situación profesional del autor resultan omnipresentes en sus relatos y forman parte del proceso de creación de su nueva identidad.

Ya en las primeras páginas de La emoción del nómada el viajero habla sobre su situación profesional. La preocupación por su estatus se hace visible desde el principio y Silvestre afirma: "yo antes era escritor. Ahora no era nada" $(2013: 25)^{6}$. Ya en estas primeras líneas llama la atención la necesidad que tiene el protagonista de definirse, señalando que lo contrario de ser escritor es "no ser nada". El autor desarrolla su reflexión comentando el poco éxito de sus libros: "también es cierto que como novelista no tenía casi lectores. Los libros de Miquel Silvestre recibían buenas críticas, pero pocos los compraban" (2013: 25). Asimismo, hace hincapié en la dificultad de vivir de la literatura: "una vez vi un reportaje en televisión sobre los Balcanes. Le preguntaban a un escritor serbio si en Serbia se podía vivir de la literatura. "Sí, contestó, pero no todos los días. España no me parecía diferente a Serbia en ese sentido" (2013: 25). Dado que escribir no le permite ganarse la vida y la literatura no parece ser un oficio que dé seguridad económica, Silvestre opta por un futuro como funcionario: "por eso me había hecho registrador, para escribir lo que me diera la gana sin preocuparme de si vendía o no" (2013: 25). Sin embargo, no escribir le hace infeliz y ser registrador de la propiedad no le abre espacios de escritura, más allá de textos oficiales, referentes a su trabajo, que él mismo califica de manera negativa como "paja leguleya y aburrida" (2013: 25). Esta insatisfacción le lleva a la decisión de pedir una excedencia para escribir una novela:

Mi propósito era simple: irme a Irlanda, estudiar inglés y encerrarme delante de un ordenador con mi taza de té por las tardes y mis pintas de Guinness por las noches. Así

\footnotetext{
6 Sus obras, antes de haber publicado La emoción del nómada (2013), eran, entre otras, Mariposas en el cuarto oscuro (2003), La dama ciega (2005) y Spanya SA (2008), así como la colección de relatos Dinamo estrellada (2004), todas ellas publicadas en Ediciones Barataria.
} 
imaginaría un enrevesado argumento literario. Yo buscaba una ficción que me reconciliase con la Literatura. (2013:25)

En este fragmento ya se observa claramente que la imagen que Silvestre tiene de sí mismo como escritor abarca una visión de la vida que quiere llevar y en la que la escritura se revela como una necesidad, una herramienta para expresarse y para realizarse como sujeto.

Antes de acabar su excedencia, el autor realiza un viaje en moto por Italia y la experiencia le cautiva hasta tal punto que se declara enfermo de viaje, y considera que esta podría ser su nueva forma de vida ${ }^{7}$. No obstante, reconoce los problemas de escasez de ingresos que tiene que superar $y$, por cuestiones económicas, se ve obligado a seguir publicando en la prensa especializada de registradores, que define como "literatura átona y tediosa" (2013: 240). Al mismo tiempo, manda sus primeros reportajes de viaje a periódicos como $A B C$ o $E I$ País, pero es consciente de que esta forma de vida no es sostenible: "sé que no es una actividad a largo plazo y se me termina el dinero" (2013: 240).

En esta situación, el autor decide unir su actividad de motero con su vocación literaria, definiendo así su nuevo oficio: "entro en mi pequeño dormitorio y me acuesto feliz bajo un techo de madera. Me encanta esta forma de vida. Es la mía. Cavilo en cómo lograr que esto dure. Decido que tengo que convertirme en escritor de viajes" (2013: 223). Desde la lejana estepa kazaja el autor llama a su familia para informarles del destino que quiere como registrador de la propiedad, pero sabe que esta ocupación va a ser provisional, ya que su meta está en otro sitio: "hoy he decidido que mi objetivo será convertirme en viajero profesional para no tener que seguir engañándome haciendo un trabajo que no me gusta" (2013: 249). La decisión de convertirse en escritor de viajes va más allá de la necesidad de pensar cómo estructurar su propio relato o de la

\footnotetext{
${ }^{7}$ La idea de la "enfermedad de viaje" que se materializa en la necesidad del desplazamiento constante puede considerarse ya una especie de tópico. Las grandes figuras del género como Bruce Chatwin, Ryszard Kapuściński o Javier Reverte parecen convencidos de la existencia de este impulso que hace rechazar el sedentarismo y convertir la vida en un movimiento continuo. Javier Reverte, en El sueño de África, afirmaba: "cuando el veneno de viajar entra en tu sangre, no es preciso ir en busca de nada y hay que emprender camino" (2004: 20). Asimismo, Chatwin ponía como un ejemplo de nómada por elección a Stevenson, que en una carta a su madre confesaba: "tienes que recordar que seré un nómada, más o menos, hasta el fin de mis días" (1997: 144).
} 
transformación que conlleva el viaje, es un paso hacia la creación de una nueva identidad, de verse y definirse de una manera distinta. La vocación literaria de Silvestre y su necesidad de hacer de ella una forma de vida se convierten en una de las preocupaciones centrales del autor.

En la siguiente obra, Nómada en Samarkanda (2016), el protagonista ya habla de sí mismo como escritor viajero profesional e insiste en la importancia del viaje y de la escritura como su único empleo. Es feliz por haber conseguido su sueño de "viajar de modo profesional y ser escritor de viajes" (2016: 19). En la conversación con un policía italiano que quiere ponerle una multa por haber accedido en moto al centro histórico vemos cómo a Silvestre le gusta presentar el viajar y el escribir como sus oficios: “- ¿A Uzbekistán? ¿En esa moto? - Sí, verá, he dado la vuelta al mundo y éste es mi trabajo. Viajar, fotografía, filmar y escribir" (2016: 60). Asimismo, también se presenta como escritor a otros viajeros con los que se cruza por su camino: "suelo decir que soy escritor y que por eso sé de palabras y no de bielas" (2013: 163).

Silvestre ya no es solo un motero que viaja por tierras lejanas, ahora mismo también es un escritor profesional consciente de ciertos requisitos que este tiene que cumplir:

Al lado, un nutrido grupo de personas discutía a voz en cuello. Había militares y civiles. Gesticulaban con muchos aspavientos. Su presencia era ruidosa y molesta. Aunque a mí ya nada me importunaba. Podría haberme replegado hacia mi interior y dormir despierto para aislarme del incómodo exterior. No quise hacerlo. En lugar de eso, y a pesar de que no me apetecía, me obligué a fijarme en ellos. Eso es lo que hace un escritor, diablos, me dije, se fija en las cosas... (2016:10)

Observamos una especie de código de lo que debería hacer un escritor profesional de viajes. Por esta razón, la idea de ganarse la vida escribiendo y viajando modifica la propia experiencia del viaje, le hace actuar al sujeto de una determinada forma. Su experiencia del viaje, a lo mejor, sería muy distinta si no quisiera verse y presentarse como un escritor profesional. Él mismo es consciente de que su nueva profesión determina su manera de vivir el viaje, ya que ser un viajero-escritor profesional no es lo mismo que ser un simple motorista:

No me quejo. Sería injusto y estúpido. Me gusta mi trabajo, me apasiona, pero a veces añoro el viajar sin obligaciones, sin deberes autoimpuestos. Por ejemplo, ahora mismo, 
cuando lo que me gustaría es ser un simple motorista que recorre la Costa Dálmata para disfrutar del pilotaje y el escenario. (2016: 78)

Estas obligaciones y deberes autoimpuestos, el resultado de su decisión de ser escritor de viajes, hacen que su experiencia esté atravesada por la rutina del escritor: "aprovecho para ponerme al día con mis muchas tareas pendientes. Un vídeo, seguir con el libro de Asia Central que espera con impaciencia mi editor y que llevará de título La emoción del Nómada y responder a mil mensajes y correos" (2016: 47).

Como vemos, durante su segundo viaje, Silvestre se dedica a preparar lo que fue su primer recorrido por Asia Central. Asimismo, el viajero menciona la necesidad de "responder a mil mensajes y correos" lo que nos conecta con otra faceta de su vida como escritor. En el mundo interactivo, para poder mantenerse en la industria cultural, resulta muy necesario estar en las redes sociales y mantener el contacto constante con sus lectores o los que ven sus vídeos y fotos:

\footnotetext{
Y, además, hay algo que también compensa el esfuerzo. Tener lectores. No llegaría a ellos si no estuviera en las redes sociales, si no publicara en Solo Moto, sino [sic] subiera vídeos a Youtube. Y para un escritor la satisfacción de compartir su alma con lectores reales es el más dulce premio a su sacrificio, así que lo doy por bienvenido y acometo mis muchas tareas pendientes. (2016: 47)
}

Asimismo, tampoco le pasan desapercibidas las críticas que recibe, las comenta y las relaciona con la envidia de quienes no pueden realizar un viaje como él:

Asuntos de trabajo, mensajes de ánimo de seguidores, insultos de envidiosos virtuales... En fin, la rutina del viajero profesional que encarna los sueños de aventura de muchos que no pueden vivirlos en primera persona y que o los disfrutan de modo vicario $u$ odian de forma irracional a quien sí los vive. Esto último es algo que no llego a entender del todo. ¿Para qué comprarte una moto aventurera que no vas a llevar de aventura y para qué seguir a los aventureros para criticarlos y aborrecerlos? Esa actitud me resulta incomprensible. (2016: 123)

Estas críticas le preocupan en el plano personal, pero también es consciente de que su éxito en el mercado depende de las opiniones favorables. El hecho de tener o no tener seguidores en las redes sociales o poder contar con lectores de sus obras es lo que marca la diferencia entre poder vivir del viaje y la escritura 0 no. Por esta razón, le dedica tanto espacio a estas cuestiones en su obra.

De la misma manera, a lo largo de ambos relatos, resulta omnipresente la idea de haber dejado un trabajo seguro para adentrase en el mundo literario, 
lleno de incertidumbre. Silvestre comenta, por ejemplo, que unos franceses que conoce en el camino "alucinan cuando se enteran de que en España trabajaba de lo que ellos conocen como conservateur des hypotheques. No me imaginan con corbata. Yo tampoco puedo reconocerme ahora ahorcado por una de ellas" (2013: 222). La oposición entre la vida anterior, simbolizada por la corbata que "ahorca" al sujeto, y la realidad actual de libertad absoluta gracias al viaje es evidente. Silvestre se presenta como quien se atreve a cambiar su realidad, oponiéndose a todos aquellos que no son capaces de tomar esta decisión y se quedan en el mundo de compromisos y obligaciones que él ha abandonado. Por esta razón, comenta que la jefa de personal de la BDO en Ucrania "dice que le gustaría mucho viajar como yo, pero que no puede, tiene que trabajar" (2013: 79). También recuerda a un hombre que en Eslovenia le confiesa: "vivo en Belgrado y tengo una GS 1200. Sueño con hacer un día lo que tú haces" (2016: 71). Asimismo, el motero le cede la voz al trabajador de una empresa canadiense que "asegur[a] envidiar [su] destino de hombre libre" (2016: 223).

La construcción de la nueva identidad del protagonista es evidente y ocupa una gran parte de sus relatos. Silvestre no solo cuenta sus viajes, sino también da cuenta del proceso de su creación como sujeto nuevo, su conversión en un profesional del viaje y la escritura. Todo esto contribuye a que en sus textos aflore la subjetividad del protagonista que reflexiona sobre su carácter y su vida:

\footnotetext{
Paseo, miro, aprendo y escribo. Soy simplemente yo. Me siento cómodo dentro de mi piel. Creo que nunca me había sentido tan abierto, tan receptivo, tan conforme con mi vida y conmigo mismo. Supongo que de algún modo a todos nos cuesta aceptarnos. Reconocernos como legítimos miembros de la especie. Para mí no ha sido fácil. Nunca lo fue. (2013: 324)
}

Tal y como confiesa el propio autor, convertirse en escritor de viajes significa reconciliarse con uno mismo y supone el fin de la crisis de identidad que experimentaba trabajando en lo que no le hacía feliz. Por lo tanto, tomar la decisión de convertir el viaje y su escritura en una forma de vivir significa construirse a sí mismo. 


\section{Conclusiones}

Miquel Silvestre, en sus relatos, no solo reflexiona sobre la experiencia del viaje y su puesta por escrito, sino también se interroga constantemente por el valor y, sobre todo, el papel de estas experiencias en su vida. Al ser consciente de que estas constituían tan solo un paréntesis en sus actividades cotidianas, decide convertirlas en esenciales, haciendo de ellas su nuevo proyecto vital. De esta forma, la construcción de su nueva identidad pasa inevitablemente por el viaje y la escritura. Ser escritor de viajes se convierte en su nuevo signo de identidad.

Estas decisiones vitales se ven reflejadas en su escritura, ya que sus relatos están atravesados por reflexiones sobre el estatus profesional del protagonista. Tanto en La emoción del nómada como en Nómada en Samarkanda el autor acentúa reiteradamente su faceta de escritor profesional. El propio relato se revela, en cierta medida, como una justificación de la decisión vital de su autor. También en el plano de la propia experiencia, podemos observar que el viaje está condicionado y limitado por esta nueva profesión: a veces el autor se ve obligado a hacer cosas que no le apetecen, y en sus obras comenta su rutina de escritor y los deberes siempre presentes de escribir, editar o cumplir con los plazos. Las leyes del mercado, que obligan a los autores a estar siempre presentes en las redes sociales, interactuar con su público y promocionar constantemente su propia obra, también se ven reflejadas en las reflexiones de Silvestre.

Por esta razón, la decisión de escribir y viajar como oficio está indisolublemente unida a la formación de la identidad del autor y a la creación de un nuevo sujeto, al mismo tiempo que afecta y modifica tanto la escritura de este autor como su experiencia del viaje.

\section{Bibliografía}

AlbuRQUERQUE-GARCía, Luis (2006). "Los 'libros de viaje' como género literario". En Manuel Lucena Giraldo y Juan Pimentel (eds.), Diez estudios sobre viaje. Madrid: CSIC, pp. 67-89.

AlBURQUERQUE-GARCíA, Luis (2011). "El 'relato de viajes': hitos y formas en la evolución del género", Revista de Literatura, LXXIII, 145, pp. 15-34.

AlBURQUERQUE-GARCíA, Luis (2015). "Relatos de viaje' y paradigmas culturales", 
Letras, 71, pp. 63-76.

ALMARCEGUI, Patricia (2008). "Viaje y literatura: elaboración y problemática de un género", Letras, 57-58, pp. 25-31.

BELTRÁN LLAVADOR, Rafael (1991). "Los libros de viajes medievales castellanos", Revista de Filología Románica, anejo 1, pp. 121-164.

Benjamin, Walter [1972] (1991). Para una crítica de la violencia y otros ensayos, Iluminaciones IV. Madrid: Taurus.

BoulNoIS, Luce [2001] (2004). La Ruta de la Seda: dioses, guerreros y mercaderes. Barcelona: Península.

Carrizo Rueda, Sofía (1997). Poética del relato de viajes. Kassel: Edition Reichenberger.

Colombi NicoliA, Beatriz (2006). “El viaje y su relato”, Latinoamérica, 43, pp. 1135.

ChAMPEAU, Geneviève (2004), "El relato de viaje, un género fronterizo". En Geneviève Champeau (ed.), Relatos de viajes contemporáneos por España y Portugal. Madrid: Verbum, pp. 15-31.

ChatWIN, Bruce (1997). Anatomía de la inquietud. Madrid: Anaya \& Mario Muchnik.

GonZÁLEZ-RIVERA, Juliana (2019). La invención del viaje. Madrid: Alianza.

ONFRAY, Michael [2007] (2016). Teoría del viaje. Madrid: Taurus.

Peñate Rivero, Julio (2004). "Camino del viaje hacia la literatura". En Julio Peñate Rivero (ed.). Relato de viaje y literaturas hispánicas. Madrid: Visor Libros, pp. 13-28.

Peñate Rivero, Julio (2015). "La poética del libro de viaje entre la Edad Media y el siglo XXI", Letras, n.o 71, pp. 41-62.

Pérez Priego, Miguel Ángel (1984). "Estudio literario de los libros de viajes medievales", Epos 1, pp. 217-240.

Peris Blanes, Jaume (2010). "Viaje, experiencia y narración: de las notas viajeras de Guevara a Diarios de la Motocicleta", Espéculo. Revista de estudios literarios, n. 0 46, s.p.

Regales Serna, Antonio (1983). "Para una crítica de la categoría literatura de viajes", Castilla, n.. 5, pp. 63-85.

REVERTE, Javier (2004). El sueño de África. Barcelona: DeBolsillo.

RICHARD, Jean (1981). Les récits de voyages et de pèlerinages. Turnhout: Brepols.

RousseAU, Jean Jacques [1762] (1998). Emilio, o De la educación. Madrid: Alianza.

Rubio MaRTín, María (2011). "En los límites del libro de viajes: seducción, canonicidad y transgresión de un género", Revista de Literatura, n. 73, pp. 65-90.

RuBIO, Pilar (2006), "Nuevas estrategias en la narrativa de viajes contemporánea". En Manuel Lucena Giraldo y Juan Pimentel (eds.), Diez estudios sobre viaje. Madrid: CSIC, pp. 243-256.

SILVESTRE, Miquel (2013). La emoción del nómada. Barcelona: Comanegra.

SILVESTRE, Miquel (2016). Nómada en Samarkanda. Madrid: Silver Rider Prodaktions.

ThOMPSON, Carl (2011). Travel Writing. Londres, Nueva York: Routledge.

YounGs, Tim (2013). The Cambridge Introduction to Travel Writing. Cambridge: 
Cambridge University Press.

ZYGMUNT, Karolina (2021), Viajar y escribir en la era del turismo de masas.

Relatos de viajes contemporáneos por la Ruta de la Seda. Madrid: CSIC.

Fecha de recepción: 13 de septiembre de 2021

Fecha de aceptación: 11 de noviembre de 2021 